\title{
Looking at the evidence
}

The requirement that medical treatment is 'evidencebased' has become an essential part of modern healthcare practice. In the UK, the National Institute for Health and Clinical Excellence (NICE) has developed guidance to achieve national consensus on best practice. The role of NICE has often attracted controversy, particularly when expensive new treatments are considered on the basis of cost-effectiveness, and difficult and sometimes unpopular recommendations have been made. In this issue of The Journal of Laryngology \& Otology, a key review article examines the guidance of NICE relevant to otolaryngology. ${ }^{1}$ The authors consider the work of NICE essential both in the introduction of new technology but also in the evaluation of previously accepted methods of treatment. Key guidelines have been issued concerning such topics as cochlear implantation, sinus balloon dilatation, palatal surgery for snoring and tonsillectomy techniques, as well as many others.

In a previous article published in the Journal, the increase in the number of females sustaining nasal fractures in the UK was attributed to a 'ladette culture' that often revolves around nightclub attendance. ${ }^{2}$ An article in the current issue discusses university students' attitudes towards noise-induced hearing loss caused by nightclub attendance. ${ }^{3}$ A high proportion of students reported symptoms related to noise-induced hearing loss, and most of them felt that noise in nightclubs should be limited to safe volumes.

In rhinological practice, the use of nasal saline rinses has seen a resurgence, with evidence of efficacy in terms of symptom relief. ${ }^{4}$ Many different nasal saline preparations are commercially available. Elmiyeh and colleagues compared three commonly available nasal saline solutions in the UK, and concluded that there are differences in the quality of patient instructions and ease of use. ${ }^{5}$ The practice of aesthetic surgery has also been in the spotlight, particularly in the light of the recent breast implant scandal in the UK. Adherence to the highest ethical principles is essential in all fields of surgery, but in aesthetic surgery it is paramount. In aesthetic facial surgery, knowledge of potential pitfalls, particularly in patient selection and counselling for surgery, is vital. Veer and colleagues, in an excellent article, provide a comprehensive review of pre-operative considerations in aesthetic facial surgery that should be essential reading for anyone considering practice in this field. ${ }^{6}$

ROBIN YOUNGS

EDWARD FISHER

Editors

\section{References}

1 Aval S, Pabla L, Flood LM. The National Institute for Health and Clinical Excellence, and otolaryngology: review of the evidence. J Laryngol Otol 2014;128:2-12

2 Trinidade A, Buchanan MA, Farboud A, Andreou Z, Ewart S, Mochloulis $\mathrm{G}$ et al. Is there a change in the epidemiology of nasal fractures in females in the UK? J Laryngol Otol 2013; 127:1084-87

3 Johnson O, Andrew B, Walker D, Morgan S, Aldren A. British university students' attitudes towards noise-induced hearing loss caused by nightclub attendance. J Laryngol Otol 2014;128: 29-34

4 Harvey R, Hannan SA, Badia L, Scadding G. Nasal saline irrigations for the symptoms of chronic rhinosinusitis. Cochrane Database Syst Rev 2007;(3):CD006394

5 Elmiyeh B, Heywood RL, Prasad VMN, Chatrath P, Bassett P, Quiney R. A prospective, single-blind, randomised, crossover study comparing three nasal hygiene systems and corresponding patient preference for such devices. J Laryngol Otol 2014;128: 73-77

6 Veer V, Jackson L, Kara N, Hawthorne M. Pre-operative considerations in aesthetic facial surgery. J Laryngol Otol 2014;128: $22-28$ 